TIME

\title{
Soft porous crystal meets TCNQ: charge transfer-type porous coordination polymers
}

\author{
$\operatorname{AUTHOR}(\mathrm{S})$ :
}

Shimomura, Satoru; Kitagawa, Susumu

\section{CITATION:}

Shimomura, Satoru ... [et al]. Soft porous crystal meets TCNQ: charge transfer-type porous coordination polymers. Journal of Materials Chemistry 2011, 21(15): 5537-5546

\section{ISSUE DATE:}

2011

URL:

http://hdl.handle.net/2433/156524

\section{RIGHT:}

(c) The Royal Society of Chemistry 2011.; This is not the published version. Please cite only the published version.; この論文は出版社版で ありません。引用の際には出版社版をご確認ご利用ください。 


\title{
Soft Porous Crystal meets TCNQ: Charge Transfer-Type Porous Coordination Polymers
}

\author{
Satoru Shimomura ${ }^{a}$ and Susumu Kitagawa ${ }^{a b c}$ \\ ${ }^{a}$ Department of Synthetic Chemistry and Biological Chemistry, Graduate School of Engineering, \\ Kyoto University, Katsura, Kyoto 615-8510, Japan. \\ ${ }^{b}$ ERATO Kitagawa Integrated Pores Project (Japan), Kyoto Research Park Bldg \#3, Shimogyo-ku, \\ Kyoto 600-8815, Japan. \\ ${ }^{c}$ Institute for Integrated Cell-Material Sciences, Kyoto University 69 Konoe-cho, Yoshida, Sakyo-ku, \\ Kyoto 606-8501, Japan. \\ E-mail: kitagawa@icems.kyoto-u.ac.jp
}

\section{Abstract}

The significant progress of porous coordination polymers (or metal-organic frameworks) has been attaching attention of a lot of scientists in various disciplines and encouraging their entry into this field. The synergy of diverse scientific senses brings further spread of the chemistry of porous coordination polymers. In this review, we introduced the recent developments in PCPs resulting from the hybridization with TCNQ chemistry. Electronic and structural diversities of TCNQ provide novel and advanced porous properties, when they are hybridized with a flexible nature of porous coordination polymers.

\section{Introduction}

The history of porous materials goes back to the beginnings of human civilization and advances together with the development of humankind. Activated carbons, which are oldest and most famous porous materials, were used in a medical setting from as early as 1500 B.C. ${ }^{1}$ Industrial applications originated in the late $18^{\text {th }}$ century, when it was discovered that activated carbons could adsorb gases and remove color bodies from solution. These features come from the randomness of the amorphous structure with various pore sizes and pore shapes. Activated carbons have been being used extensively in manifold applications because of the inexpensive and convenient source and the simple synthetic method. ${ }^{1,2}$ Then, many kinds of porous materials, such as Zeolites were discovered and synthesized one after the other and used in various situations. Zeolites, which were found in the middle of the $18^{\text {th }}$ century, are crystalline hydrated alkaline or alkaline-earth aluminosilicates containing pores and cavities. ${ }^{3}$ Today, they are widely used in industrial applications with their crystallographically defined pore structures and high thermal and chemical stabilities. ${ }^{4,5}$

At the end of the 20th century, the appearance of the new porous compound with inorganic-organic hybrid framework made an impact on the field of porous materials and added a new category to the conventional classification. Porous coordination polymers (PCPs), also known as metal organic frameworks (MOFs), have complete regular micropores, resulting in the quite large pore surface area, and highly designable framework, pore-shape, pore-size and surface functionality. ${ }^{6-29}$ Their structures are constructed by the organic ligands as linkers and the metal centers as the connectors. PCPs get both variety and functionality of the organic materials and directivity and regularity of the inorganic materials. These components are connected by coordination bonds and other weak interactions or non-covalent bonds (H-bonds, $\pi$-electron stacking or van der Waals interaction) to form an infinite network. These interactions with smaller binding energy than that of a covalent bond cause the structural flexibility and dynamics in the crystalline state, which heightens a singularity of PCPs in the field of porous materials. ${ }^{30}$

Over the past dozen years since the beginning of PCPs, They have been attracting the attention of many scientists from various fields because of interest in the creation of amazingly versatile 
nanometer-sized spaces and the novel phenomena that occur in them. Currently, Studies on PCPs involve not only basic coordination chemistry but a wide range of fields such as Synthetic organic chemistry and Physical chemistry. This kind of hybridization of the scientific fields leads to give epochal advances in this field and create a new chemistry. Among them, approaches from chemistry of organic conductors and charge transfer complexes increase their presence. While the previous researchs on PCPs focused on a construction and analysis of nano-porous structure, these approaches exploring unexpected electronic properties with redox active modules contribute to further development of PCPs. In this field, Tetracyanoquinodimethane (TCNQ) is one of the most famous redox active molecules, and there are an enormous number of researches using this molecule and they are still increasing. ${ }^{31-37}$ Also in the field of PCPs, some porous frameworks based on TCNQ have been synthesized and showing various phenomena depending on the unique electronic property of TCNQ.

\section{TCNQ chemistry}

TCNQ first appeared in 1960 by E. I. du Pont de Nemours and Company. ${ }^{38}$ TCNQ is the historical example of an acceptor molecule which can be easily reduced to form the open shell anion radical $\mathrm{TCNQ}^{-}$when it is placed in contact with electron donors. TCNQ is also known as a decent multi-redox-active molecule; it can easily accommodate two extra electrons and, in some case, the radical trianion can even be formed. Diverse kinds of charge transfer complexes have been created with inorganic and organic donors. A charge transfer complex with a strong organic donor Tetrathiafulvalene (TTF); TTF-TCNQ particularly received the attention of the entire world at that time when it was synthesized. ${ }^{39}$ TTF-TCNQ is the prototype of the charge-transfer compounds where HOMO and LUMO bands of the open shell donors and acceptors, respectively, contribute to the conduction. It has also been the first organic conductor to present a large conductivity in a wide temperature domain down to $59 \mathrm{~K}$, where a sharp metal to insulator transition is observed. ${ }^{40}$ The exceptional charge-transfer characters of them leaded to such unexpected electron properties. In this system, they are uniformly segregated and stacking with $\pi$ orbitals contributing to two conduction bands. The $\pi$ stacked column structure like this is common among the TCNQ based compounds and becomes the basis of their great electric and magnetic properties.

On the other hands, one of the important factors to be considered in the compounds of TCNQ is the high $\sigma$-donor ability of TCNQ species. The presence of four widely separated cyano groups which can act as coordination sites renders TCNQ as potentially polydentate bridging ligands capable of binding up to four metal centers. ${ }^{35,} 36$ Various kinds of metal-TCNQ complexes have been synthesized with the several coordination modes, such as $\mu_{1}$, syn- $\mu_{2}, c i s-\mu_{2}, \mu_{3}$, and $\mu_{4}$. Because of the structural and electronic diversity of TCNQ, a number of scientists have been interested in the interactions of TCNQ and metal ions leading to the studies of electron transfer phenomena and the unusual physical properties in solid state.

One of the typical coordination polymers are TCNQ radical anion complexes with monovalent metal ions: $\mathrm{M}(\mathrm{TCNQ})(\mathrm{M}=\mathrm{Cu}(\mathrm{I}), \mathrm{Ag}(\mathrm{I})) .{ }^{34}{ }^{41}$ These were synthesized early in the history of TCNQ, and exhibited bistable switching phenomena in electron conductivity, which were induced by electric field and photo irradiation. ${ }^{42,}{ }^{43}$ Despite the extensive effort devoted to understanding this unique properties of these compound ${ }^{44}$ and, especially in the case of $\operatorname{Ag}(\mathrm{TCNQ})$, the structural analysis was succeeded, ${ }^{41}$ there still remained skepticism regarding the validity of the mechanism, which were proposed in the original report. Meanwhile, Dunbar and co-workers reported the critical insights into the mechanism. ${ }^{45}$ They characterized the structures and the conducting properties of two polymorphs of $\mathrm{Cu}(\mathrm{TCNQ}$ ) (phase I and phase II) and suggested these two phases with different electron conductivities are deeply involved with the switching phenomena (Figure 1). In phase I the TCNQ units form close $\pi$-stacking column structure at about $3.24 \AA$ intervals whereas in phase II the closest distance of the $\pi$ surfaces are about $6.8 \AA$. The column structure of TCNQ significantly affects the conducting mechanism, and this is why the difference of electron conductivities in phase I and II was observed. From this report to the present, many researchers have reported about this compound to achieve the construction and the control of nanostructure and the incorporation into nano-device system. $^{46-48}$ 
About some dozens of coordination polymers with TCNQ have been synthesized so far. However there are not so many compounds, various studies about the magnetic properties based on the organic-inorganic hybrid infinite networks have been energetically carried out. In particular, Miyasaka, Dunbar and co-workers have synthesized various kinds of crystal structures of coordination polymers with TCNQ and its derivatives, and revealed their unique magnetic behaviors. The 2D coordination network systems composed of the paddlewheel-type dimetal units and TCNQ derivatives are one of the platforms which were adopted by their group to create the molecular based magnetic-conducting materials (Figure 2) ${ }^{49-51}$ In these systems, the dimetal units acting as electron donors and the TCNQ derivatives acting as electron acceptors form charge transfer complexes and showing a charge transfer resonance, which leads to the long range strong magnetic interactions and/or metallic properties. These properties are deeply affected by the degree of charge transfer between the dimetal units and the TCNQ derivatives. Only the compound with the diruthenium $\left[\mathrm{Ru}_{2}{ }^{\mathrm{II}, \mathrm{II}}\left(\mathrm{O}_{2} \mathrm{CCF}_{3}\right)_{4}\right]$ units and $\mathrm{TCNQF} \mathrm{F}_{4}$ exhibits 3-D long-range antiferromagnetic order at $95 \mathrm{~K}$ because of the full charge transfer from $\left[\mathrm{Ru}_{2}{ }^{\mathrm{IIII}}\right]$ to $\mathrm{TCNQR}$ to give the formal resonance form $\left[\left\{\mathrm{Ru}_{2}{ }^{4.5+}\right\}-\left(\mathrm{TCNQF}_{4}{ }^{-}\right)-\left\{\mathrm{Ru}_{2}{ }^{4.5+}\right\}\right]$, compared with the isostructural compounds which are in the quasi-static state of $\left[\left\{\mathrm{Ru}_{2}{ }^{4+}\right\}-\left(\mathrm{TCNQR}_{\mathrm{x}}{ }^{0}\right)-\left\{\mathrm{Ru}_{2}{ }^{4+}\right\}\right]$ without charge transfer between the $\left[\mathrm{Ru}_{2}{ }^{\mathrm{IIII}}\right]$ and $\mathrm{TCNQR}_{\mathrm{x}}$. The charge transfer capability and properties as organic radical of TCNQ derivatives should be beneficial in the construction of the long range magnetic interactions in molecular-based magnets.

TCNQ can provide various coordination architectures as a multidentate ligand as described above. In addition, TCNQ sometimes shows the formation of multimeric complexes which expands the structural diversity of the coordination frameworks, and especially, dimerization of the TCNQ radicals with $\sigma$ bond leads to the enormous changes of molecular structure and electronic state. ${ }^{52}$ The $\sigma$ bonded dimer, (TCNQ-TCNQ) is formed by the linking of two TCNQ radical anions and a divalent anion. The $\pi$-conjugated structure of whole TCNQ molecule is ruptured by the $s p 3$ type bond formation and the negative charges localize in each TCNQ moieties. However there are few reports about the $\sigma$ bonded (TCNQ-TCNQ) ${ }^{2-}$ and in most cases (TCNQ-TCNQ) ${ }^{2-}$ have no interaction with the metal fragment, coordination polymers with $\mathrm{Mn}$ and (TCNQ-TCNQ) ${ }^{2-}$ have been synthesized and show fascinating structures and unique properties. ${ }^{53,54}$ The structure of $\left[\mathrm{Mn}(\mathrm{TCNQ}-\mathrm{TCNQ})(\mathrm{MeOH})_{4}\right]$ involves a $2 \mathrm{D}$ network composed of six-coordinate $\mathrm{Mn}$ ions equatorially bound to the four cyanide groups of (TCNQ-TCNQ) ${ }^{2-}$ ligands. The axial sites are coordinated by the two $\mathrm{MeOH}$ molecules. The as-synthesized compound exhibits Curie-Weiss behavior with a small contribution from antiferromagnetic coupling at low temperature. On the other hand, when the compound was heated at $160^{\circ} \mathrm{C}$, it exhibited a ferromagnetic transition at about $50 \mathrm{~K}$. This drastic change of magnetic property comes from the cleavage of the weak $\sigma$ bond in $(\mathrm{TCNQ}-\mathrm{TCNQ})^{2-}$ and the generation of TCNQ radical anions from this process. As the case of this compound, TCNQ is the versatile unit to produce the conducting or magnetic properties and the switchable systems because of the electronic and structural diversity.

\section{Chemistry of porous coordination polymer}

Coordination polymers (CPs) are a family of compounds with extended structures formed by metal ions and organic and/or inorganic ligands with coordination bond. In the solid state CPs provide various frameworks constructed from one-, two-, and three-dimensional $\mathrm{CP}$ motifs. The name "coordination polymer" was already used at $1916,{ }^{55}$ there were no means to demonstrate infinite frameworks without single crystal X-ray crystallography. By utilizing inorganic $\mathrm{CN}$ bridging ligand, a three-dimensional coordination framework has been already realized in 1936, which is Prussian-blue compound ${ }^{56} \mathrm{~A} X$-ray crystal structure of a metal-organic coordination framework of $\left.[\mathrm{Cu} \text { (adiponitrile) })_{2}\right] \mathrm{NO}_{3}$, which is nowadays, called MOF, appeared in 1959. Since then an enormous number of compounds have been synthesized and crystallographically characterized so far. They also included the potential porous systems, possessing pore spaces which are filled with solvent molecules or counter ions. They are regarded as Clathrate-type CPs, however, which are not real "porous" compounds. Therefore, we have to wait that the concept of "porosity" is realized by a compound having a porous structure without guests in the pores until 1997 when porous $\mathrm{CP}$ has been 
prepared and gas sorption experiment was carried out for the stable apohost. ${ }^{57}$ Since the gas storage or sorption properties are discovered, PCPs have attracted worldwide attention as new porous materials with highly regular micropores. At that time, there are not so many compounds which can show porous properties among them. Even when the compounds possess the pore space in the structure, some of them cannot maintain the open framework then collapse or irreversibly transfer to the other structure in the guest removal process. ${ }^{6}$ The fragility comes from the coordination bonds which are weaker than covalent and ionic bonds constituting the other conventional porous materials. In addition, the stability of the framework decreases as the porosity increase because of a proposition 'nature abhors a vacuum' (Aristotle). Therefore, a lot of scientists have aimed to construct the robust framework with high porosity (Figure 3).

Metal organic frameworks (MOFs) composed of $\mathrm{Zn}_{4} \mathrm{O}$ clusters connected by the organic linkers are one of the well-known series of porous motifs and embody the current of study for high porosity. $\left[\mathrm{Zn}_{4} \mathrm{O}(\mathrm{BDC})_{3}\right]$ (MOF-5) was synthesized early in the PCPs history and possess a cubic structure with 1,4-benzenedicarboxylate (BDC) as a organic linker. ${ }^{58}$ On the basis of this motif, many porous compounds have been synthesized with using other dicarboxylate linkers, and this approach leads to some positive results to increase the pore volume according to the length and shape of the organic ligand. ${ }^{59}$ PCPs having tricarboxylate linkers such as $\left[\mathrm{Zn}_{4} \mathrm{O}(\mathrm{BTB})_{2}\right](\mathrm{MOF}-177)$ and $\left[\mathrm{Zn}_{4} \mathrm{O}(\mathrm{BBC})_{2}\right]$ (MOF-200) also possess quite high porosity; the pore volumes reach as high as 90 percent of the lattice in the latter case. ${ }^{60,61}$ The $3 \mathrm{D}$ framework $\left[\mathrm{Cu}_{3}(\mathrm{TMA})_{2}\left(\mathrm{H}_{2} \mathrm{O}\right)_{3}\right]$ (HKUST-1) including $\mathrm{Cu}_{2}$ paddle wheel units linked by the trimesic acid (TMA) is also one of the early PCP and a highly porous system. ${ }^{62}$ This compound possesses a face-centered-cubic crystal structure and a 3D channel with a pore size of $1 \mathrm{~nm}$ and an accessible porosity of about 40 percent in the solid. This compound has been used for various studies because of the thermal stability and the aqueous durability of this motif. Therefore, some isostructural frameworks have been synthesized with longer tricarboxylate units and in the case of $\mathrm{Cu}_{3}(\mathrm{TATB})_{2}\left(\mathrm{H}_{2} \mathrm{O}\right)_{3}$ (PCN-6), containing 4,4',4"-s-triazine-2,4,6-triyltribenzoate (TATB) as a organic linker instead of TMA, the average diameter of the void inside the cuboctahedron is as large as $30.3 \AA .{ }^{63}$ Despite the 2-fold interpenetration of the frameworks, PCN-6 is still sufficiently porous with the pore volume of 74 percent of the lattice. There are porous systems with a quite large pore size and a highly porosity composed of only small and simple components. $\left[\mathrm{Cr}_{3} \mathrm{~F}\left(\mathrm{H}_{2} \mathrm{O}\right) \mathrm{O}(\mathrm{BDC})_{3}\right]$ (MIL-101) is made from the linkage of $\mathrm{BDC}$ units and chromium trimers units that consist of three $\mathrm{Cr}$ cations and the $\mu_{3} \mathrm{O}$ oxygen anion. ${ }^{64}$ This compound possesses a extra-large cell volume and pore size; the pore space is constructed of the two cage units with the diameters of $29 \AA$ and $34 \AA$ which are connected with the window with the diameter of $12 \AA$ and $14.5 \AA$, respectively.

Enhancement of thermal and chemical stability of porous structure is also important topic for PCPs. The compound $\left[\mathrm{Zn}(\mathrm{MeIM})_{2}\right](\mathrm{MeIM}=2$-methylimidazolate $)(\mathrm{ZIF}-8, \mathrm{ZIF}=$ zeolitic imidazolate framework) showed a one good design for this topic. ${ }^{65}$ This compound is composed of $\mathrm{Zn}$ cations and MeIM linkers and they make a $\mathrm{Zn}-\mathrm{MeIM}-\mathrm{Zn}$ angle, close to $145^{\circ}$, which is coincident with the $\mathrm{Si}-\mathrm{O}-\mathrm{Si}$ angle which is preferred and commonly found in many zeolites. This framework possesses high thermal resistivity (up to $550^{\circ} \mathrm{C}$ in $\mathrm{N}_{2}$ ) and chemical stability (in boiling water or $8 \mathrm{M} \mathrm{NaOH}$ aqueous solution). This exceptionally stable porous structure comes from the combination of a hydrophobicity of the pore surface and strong coordination bond between $\mathrm{Zn}$ and MeIM. As described above, various studies for the robustness and high porosity have been performed and are still going.

In contrast to the approach for robust porous framework, there are researches in which the fragility of PCPs is perceived as the flexibility and the dynamic properties. We can identify the compound showing guest accommodation with reversible nonporous to porous transformation as a porous material even if the compound cannot maintain the porous structure in guest removal process. These compounds are categorized as "third generation" $\mathrm{PCPs}^{6}$ and later as "Soft Porous Crystals (SPCs)", and subjected to study due to their unique properties (Figure 4). SPCs are the most unique and unprecedented porous materials. The adsorption isotherms of these compounds sometimes cannot be classified according to the conventional IUPAC classification ${ }^{66}$ because of the dynamic guest accommodation behavior. For instance, a 'gate type' sorption profile shows no uptake at low concentration of the guest molecules, and an abrupt increase in adsorption after a threshold 
concentration. This so-called gate-opening pressure is a representative characteristic of them. The behavior is associated with a structural transformation from a non-porous to a porous phase.

The compound $\left\{\left[\mathrm{Cu}(\mathrm{bpy})\left(\mathrm{H}_{2} \mathrm{O}\right)_{2}\left(\mathrm{BF}_{4}\right)_{2}\right](\mathrm{bpy})\right\}$ is the first example to show the gate type sorption phenomena in PCPs although the exact structure was not characterized when it was discovered (Figure 5a). ${ }^{67}$ This compound transforms from a $3 \mathrm{D}$ interpenetrated structure to a $2 \mathrm{D}$ square-grid layer structure $\left[\mathrm{Cu}\left(\mathrm{BF}_{4}\right)_{2}(\mathrm{bpy})_{2}\right]$ by dehydration. ${ }^{68}$ However this $2 \mathrm{D}$ sheet structure has no space to accommodate the guest molecules, the interlayer distance between the neighboring sheets increases and forms micropores with $\mathrm{CO}_{2}$ adsorption. The gate type sorption behavior for $\mathrm{CO}_{2}$ is associated with this expansion/shrinkage dynamic modulation. 2D layer structure is a good motif for the gate type sorption behavior because it is readily transformable system to respond to the guest accommodation. In particular, interdigitated layer structure is one of the most useful structures because we can control interaction between sheets by the modification of parts to be interdigitated. $\left[\mathrm{Cu}_{2}(\mathrm{dhbc})_{2}(\mathrm{bpy})\right]_{n}(\mathrm{dhbc}=2,5$-dihydroxybenzoate) has an interdigitation with $\pi-\pi$ stacking interaction of dhbc moieties as a pillar in the adjacent sheets. ${ }^{69}$ The $\pi-\pi$ stacking of the pillar parts provides a moderate interaction for stabilization of the structure, and the sliding motion of $\pi-\pi$ stacking is feasible when a guest is adsorbed to form an open structure. The structural modification affords a superb selectivity for $\mathrm{CO}_{2}$ in the mixture of $\mathrm{CH}_{4} / \mathrm{CO}_{2}$, useful for the application to an energy-saving pressure swing adsorption process. ${ }^{70}$ The compound $[\mathrm{Zn}$ (ip)(bpy)] (ip = isophthalate) (CID-1, CID = coordination polymers with an interdigitated structure) provides us with a structural platform, a CID series, in which it is easy to design the interaction between the 2D layer motifs (Figure 5b). ${ }^{71}$ The 2D layer in CID is composed of V-shaped dicarboxylate ligands, bpy and dinuclear metal units, and the dicarboxylate ligands impact on the interaction with the next layers and eventually the gate type sorption behaviors, useful for the separation of $\mathrm{CO}_{2}$ from flue gas.

Some 3D porous network systems also show the flexible feature because of the variability of coordination bond; bond cleavage and change of coordination geometry are typical triggers, and these flexibilities promote long-range structural transformation. The compound $\left[\mathrm{Cu}_{2}(\mathrm{pzdc})_{2}(\mathrm{dpyg})\right]$ (pzdc $=$ pyrazine-2,3-dicarboxylate, dpyg $=1,2$-dipyridylglycol) constructed from the neutral 2D layer with $\mathrm{Cu}$ and pzdc, and pillar ligand, dpyg, which form 3D pillared layer structure. ${ }^{72}$ This compound shows remarkable contraction of cell volume and especially of the interlayer distance by the removal of included guest molecules. The resultant framework whose channel size is not large enough to pass the molecules is classified to non-porous structure. However, the non porous phase can adsorb some solvent molecules because the transformation is reversible and the gate opening process and large hysteretic sorption isotherms can be observed. This is the first case of flexible 3D framework showing gate type sorption behavior as well as 2D layer systems. In the recent years, several researches about the gate type sorption behaviors for gas and organic molecules, and the mechanisms of them have been reported. For instance, the compound [Co(BDP)] (BDP = 1,4-benzenedipyrazolate) possessing large 1D square channels in as-synthesized state shows this type hysteretic sorption behavior even for $\mathrm{H}_{2} \cdot{ }^{73}$ Understanding of these sorption phenomena will be a linchpin of a kinetic-based storage and separation of gases.

Although the gate type sorption was not observed, flexible features of frameworks were often determined by $\mathrm{X}$-ray diffraction analysis. $\left[\mathrm{Ni}_{2}\left(4,4^{\prime} \text {-bpy }\right)_{3}\left(\mathrm{NO}_{3}\right)_{4}\right]$ have the interposing chiral bilayers of opposite handedness to form a tongue-and-groove type structure. ${ }^{74}$ The crystal structures of this compound before and after guest removal revealed the slight shrinkage of the framework based on a subtle scissor-like action of the bilayers, leading to a distortion in the configuration of the bilayers. $[\mathrm{V}(\mathrm{OH})(\mathrm{BDC})](\mathrm{MIL}-47)$ have a 3D orthorhombic structure with rhomboid-shaped channel which is delimited by four walls of benzyl units and four chains of corner-shared vanadium octahedral (Figure 6a). ${ }^{75}$ This compound and derivatives showed the expansion of the framework with guest removal and later, was used for the separation of xylene isomers in the liquid phase. ${ }^{76}$ $\left[\mathrm{Zn}_{2}(\mathrm{bdc})_{2}(\mathrm{dabco})\right]$ (dabco $=1,4$-diazabicyclo[2.2.2] octane) is an ancestral compound with typical tetragonal porous structure (Figure $6 \mathrm{~b}$ ) ${ }^{77}$ This structure is composed of square-grid 2D layer with $\mathrm{Zn}_{2}$ paddle wheel units and BDC, and pillar ligand, dabco. This compound shows the reversible induced-fit type guest accommodation behaviors with the distortion of the framework. There are many derivative compounds using other dicarboxylate ligands and/or other pillar ligands, ${ }^{78-80}$ and among them, $\left[\mathrm{Zn}_{2}(\mathrm{bdc})_{2}(\mathrm{bpy})\right]$ (MOF-508) which has interpenetrating frameworks, can separate 
linear and branched isomers of pentane and hexane as a gas chromatographic column in the GC separation system with using the distortion and slippage motions of the frameworks (Figure 6c). ${ }^{81}$ These structural dynamics in crystalline materials lead to the varied unique porous properties of PCPs. ${ }^{82,83}$

Apart from these studies focused on the construction of the framework, pore surface modification has been the important topic for PCPs. A sorption property of PCPs is strongly depended on the interactions between host framework and adsorbed guest molecules. In other words, design of hostguest interaction by adjustment of the pore surface is a shortcut to control the sorption properties of PCPs. Open or accessible metal sites are one of the popular interaction sites not only for PCPs but conventional porous materials. In early PCPs, these metal sites were accidentally produced from the "node" parts of the framework. Dimetal paddle wheel units are good motifs to create the open metal sites by removal of coordinated molecule in axial site. The $\mathrm{Cu}$ paddle wheel units in HKUST-1 act as a binding site for several gas molecules and a Lewis acidic site for the catalytic reactions. ${ }^{84}$ [Cu $\mathrm{Cu}_{2}$ (BPTC)] (MOF-505, BPTC $=3,3^{\prime}, 5,5^{\prime}$-biphenyltetracarboxylate) also possesses the $\mathrm{Cu}$ paddle wheel units linked by the BPTC and shows a good $\mathrm{H}_{2}$ storage capacity under low temperature condition, ${ }^{85,86}$ which is probably enhanced by the open metal sites. Metal-oxygen clusters are also one of the good candidates to provide the open metal sites stably. [ $\mathrm{Ni}_{2}$ (DHBDC)] (CPO-27-Ni or Ni-MOF-74), containing 3D honeycomb network with 1D large channels on which the open metal sites are uncovered after dehydration, shows the $\mathrm{CO}_{2}$ binding structure with Ni-OCO bond and high sorption energy for several gas molecules (Figure 7a). ${ }^{87,88}$ On the other hand, construction of the framework with metallo-ligands is a common strategy for introduction of open metal site on the pore surface of PCPs. ${ }^{89}$ Metallo-ligands are metal complexes that contain two or more Lewis-base sites that are able to bridge with other metal ions. The pioneering compounds with this type ligands are $[\mathrm{Cu}(\mathrm{II})(\mathrm{tpp}) \mathrm{Cu}(\mathrm{I})]$ and $[\mathrm{Cu}(\mathrm{II})(\mathrm{tcp}) \mathrm{Cu}(\mathrm{I})](\mathrm{tpp}=5,10,15,20$-tetra(4-pyridyl)-21H,23H-porphine, tcp $=5,10,15,20$-tetrakis $\left(4\right.$-cyanophenyl)-21H,23H-porphine). ${ }^{90}$ Although these porphyrin-containing frameworks do not survive removal of guest molecules, the methodology have impacted on the recent researches. The metalloporphyrin network $\left[\mathrm{CoT}\left(p-\mathrm{CO}_{2}\right) \mathrm{PPCo}_{1.5}\right]$ with large, refillable 3D channels shows selective absorption properties with regard to the hydrophilicity of guest species based on the extraordinary hydrophilic character of the open metal sites on the pore surfaces. ${ }^{91}$ The salen complex units are also a good metallo-ligand. ${ }^{92}$ The compound containing chiral salen units $\left[\mathrm{Zn}_{2}(\mathrm{bpdc})_{2} \mathrm{~L}\right] \quad(\mathrm{bpdc}=$ biphenyldicarboxylate, $\mathrm{L}=$ $(\mathrm{R}, \mathrm{R})-(2)-1,2$-cyclohexanediamino-N,N'-bis(3-tert-butyl-5-(4-pyridyl)salicylidene) $\mathrm{Mn}^{\mathrm{III}} \mathrm{Cl}$ ) is effective as an asymmetric catalyst for olefin epoxidation. ${ }^{93}$ Various kinds of functional frameworks with open metal sites have been synthesized and these studies have been increasing. ${ }^{94-96}$

Here, we should mention about the post synthetic approach; metal ions providing open metal sites are introduced into the already-formed network and entrapped by an organic linker in a pore wall. ${ }^{97}$, ${ }_{98}\left[\mathrm{Cd}_{3} \mathrm{~L}_{4}\left(\mathrm{NO}_{3}\right)_{6}\right](\mathrm{L}=(\mathrm{R})-6,6$ '-dichloro-2,2'-dihydroxy-1,1'-binaphthyl-4,4'-bipyridine) possesses the asymmetric 3D interpenetrating structure and shows enantioselective catalytic properties by the introduction of Lewis acidic metal centers (namely, Ti(OiPr) $)_{4}$ (Figure $7 \mathrm{~b}$ ). ${ }^{99}$ This postsynthetic approach is also used in the pore surface modification with organic functional groups and continues to expand rapidly. ${ }^{100}$

There are huge numbers of studies about the pore surface modification with organic ligands and they have achieved to provide various kinds of porous properties and functions by controlling the pore environment such as Lewis acidity, hydrophilicity, and polarity. As described above, a lot of compounds with kinds of porous properties in the series of $\left[\mathrm{Zn}_{4} \mathrm{O}\left(\mathrm{R}_{1}\right)_{3}\right]$ or $\left[\mathrm{Zn}_{2}\left(\mathrm{R}_{1}\right)_{2}\left(\mathrm{R}_{2}\right)\right]\left(\mathrm{R}_{1}=\right.$ dicarboxylate, $\mathrm{R}_{2}=$ pillar ligands) have been synthesized with using derivatives of dicarboxylate and pillar ligands. ${ }^{59,78,80}$ Amino-MIL-53, which is the isostructure of MIL-53 with 2-aminoterephthalic acid instead of BDC, was synthesized to enhance the affinity for $\mathrm{CO}_{2}$ against $\mathrm{CH}_{4}{ }^{101}$ In addition, This Amino-MIL-53 was used for the further postsynthetic surface modification with the synthetic organic chemical approach, and these modifications affected the selective gas sorption properties. ${ }^{102}$ In the case of $\left[\mathrm{Zn}\left(\mathrm{N}_{3}-\mathrm{ipa}\right)(\mathrm{bpy})\right]\left(\mathrm{CID}_{3} \mathrm{~N}_{3}\right)$, the pore surface properties can be changed by photoirradiation with using the photochemical reaction from azide to nitrene and this photoactivation enhances the sorption capability for $\mathrm{O}_{2}{ }^{103}$ 
However, there are few reports about the PCPs showing the strong guest accommodation by the complexation with guest molecules by the electron or charge transfer. ${ }^{104-106}$ These systems should be able to achieve the good separation and/or the unusual selectivity which it is not easy to achieve by the conventional porous compounds. To establish these systems, redox active organic molecules, which are used for organic conductors, are being used to construct the open frameworks. The hybridization of the scientific field is happening in this instant of time.

\section{Porous properties of TCNQ based frameworks}

Although some potential TCNQ based porous frameworks containing solvent molecules in the open framework have already reported in earlier times, there were few cases in which the compounds were recognized as host materials and attention focused on the release and accommodation of the guest molecules. This is because they have interesting magnetic and electric properties. The early research about the porous properties of TCNQ based coordination polymer was reported in 2006 and the compound is an insulator and a diamagnetic material. ${ }^{107}$ [ $\mathrm{Zn}$ (TCNQ)bpy] shows the pillared layer type 3D open framework composed of $\mathrm{Zn}$ (II) cation, bpy and TCNQ dianion (Figure 8a). This compound was synthesized by reacting $\mathrm{Zn}\left(\mathrm{NO}_{3}\right)_{2} \cdot 6 \mathrm{H}_{2} \mathrm{O}$ with LiTCNQ and bpy in $\mathrm{MeOH}$, without using TCNQ dianion sources and chemical reducing agents. The production process of resulting $\mathrm{TCNQ}^{2-}$ should be a disproportionation reaction of TCNQ- Although TCNQ is known as a good electron acceptor, the reducing states $\left(\mathrm{TCNQ}^{-}\right.$or $\mathrm{TCNQ}^{2-}$ ) can behave as a weak or a strong electron donor. In this framework, a dense array of strong donor sites $\left(\mathrm{TCNQ}^{2}\right)$ is formed on the pore surface, providing a highly electron rich surface for the guest molecules. Therefore, this framework can act as the electron donor and form charge transfer complex with several aromatic molecules which have the electron-accepting characteristics. This complexation brings about the recognition properties of electron acceptability of guest molecules by crystal color change. Like this approach, using co-ligands to create the space in the TCNQ compound is good methodology to form the porous framework and it is being used gradually. ${ }^{108}$

Synergy of flexible nature of PCPs and the role of TCNQ as an interaction site for guest molecules produces novel sorption system showing unusual guest accommodation behaviors. TCNQ dimer-based PCP [Zn(TCNQ-TCNQ)bpy] shows unique selective sorption properties which are rarely seen in the traditional porous materials (Figure $8 \mathrm{~b}$ ). ${ }^{109}$ This compound was synthesized under the almost same synthetic condition of the TCNQ dianion compound [Zn(TCNQ)bpy], except for the use of benzene as a template molecule. The $\mathrm{Zn}$ ions are linked by bpy to give a one-dimensional (1D) chain in the direction of the $a$-axis, and TCNQ dimer acts as cross-linker connecting the four $1 \mathrm{D}$ chains of $\mathrm{Zn}$ ions and bpy in a stepwise manner to form a 3D open framework. The channels are the undulating form, not a straight but a unique form comprising an alternating arrangement of two types of tubes of large and small diameter. By the effects of template molecule, the large diameter space fits tightly to the molecular size and thickness of benzene. Addition of the electron-rich $\pi$ surface of the TCNQ dimer forming the $\mathrm{CH}-\pi$ interaction, this framework takes on the good affinity for benzene molecule. In fact, this framework shows the unique selective sorption behavior; in contrast to no adsorption of cyclohexane, benzene can be adsorbed with the gate-open type sorption behavior and large hysteretic sorption isotherm. In addition, this framework achieves a quite high selective separation of benzene from the mixture of benzene and cyclohexane; Over $90 \%$ of the adsorbed guest molecules were benzene, even when the mixture ratio of benzene was a mere $0.1 \% .{ }^{110}$

Because the TCNQ dimer unit can act as the electron donor, this compound also shows the unprecedented selectivity for several gas molecules with electron-acceptability. Only in the cases of $\mathrm{O}_{2}$ and $\mathrm{NO}$ this compound show the sorption phenomena characteristic of the gate-type sorption behavior, In contrast to no sharp uptake over one molecule per formula was observed with any of the other gas molecules $\left(\mathrm{N}_{2}, \mathrm{CO}, \mathrm{CO}_{2}, \mathrm{C}_{2} \mathrm{H}_{2}\right.$ or $\left.\mathrm{Ar}\right) . \mathrm{O}_{2}$ and $\mathrm{NO}$ have low reduction energies and good electron acceptability compared with the other gas molecules. ${ }^{111}$ This selectivity is very rare, in particular, focusing on $\mathrm{O}_{2}$ as a target adsorbate molecule presents some difficulties because $\mathrm{N}_{2}$ has a similar shape, and $\mathrm{Ar}$ a similar size. In addition, $\mathrm{CO}_{2}$ is a good adsorbate for microporous and mesoporous materials because of its small kinetic diameter-that is, its smallest effective dimension, a parameter typically used to characterize non-symmetrical adsorbates-and good affinity for the 
adsorbent. This specific sorption ability is ascribed to the closed-open structural transformation triggered by the charge-transfer interaction between the host framework and the guest molecule. The key to this selectivity is a combination of the structural dynamics and electron-donating function of the framework, which can be induced by the soft crystallinity and designability of PCPs.

The study about a relationship between structural flexibility and sorption selectivity has been conducted by using the series of TCNQ based PCPs. In contrast to robust porous frameworks, flexibility and transformability of the framework have significant influences on the sorption properties. For that reason, this may lead to an unconventional methodology to control the porous properties without tuning the pore sizes and/or pore surface properties, even if they have identical structures. The sorption properties of the isomorphic PCPs $[\mathrm{M}(\mathrm{TCNQ}-\mathrm{TCNQ}) \mathrm{bpy}]_{n}(\mathrm{M}=\mathrm{Mn}, \mathrm{Zn})$, whose structural changes accompanying guest removal vary widely, $\mathrm{Mn}$ compound shows crystal-to-amorphous transformation and $\mathrm{Zn}$ compound shows crystal-to-crystal transformation, have been compared. ${ }^{110}$ However $\mathrm{Zn}$ compound shows exquisite separation properties, Mn compound shows not so high separation. In this system, the high selective guest accommodation of the $\mathrm{Zn}$ complex is based on the crystal-to-crystal transformation with a large energy gap. The results indicate that the flexibility of the framework is one of the important factors determining the porous properties.

TCNQ-based PCPs have been providing novel sorption properties, new insights and concepts into the field of not only PCPs but also all porous materials.

\section{Summary and outlook}

The number of reports about PCPs and MOFs has been increasing since about 2000 and to date the chemistry got various research fields in itself. Hybridization with the other scientific fields is an inevasible process in the development of PCPs and contains potential power to exploit this field and even to create other new fields. In this review, we focus on the fusion of PCPs and TCNQ chemistry, and describe the progress and the achievements of it with both historical backgrounds in mind. Now, this fusion achieved the improvement and evolution of the properties of PCPs because TCNQ acts as the unique interaction site for guest molecules. On the other hands, the improvement of TCNQ properties by the porous system is very rare. Currently, one case in which the porous structure induced the diversity of the magnetic properties based on the TCNQ-metal complex has been reported. ${ }^{112}$ But this field is still unexplored region. Achievement of synergistic activation of basic properties of PCPs, such as storage, separation, catalytic properties, and physical electronic properties of TCNQ, such as conductivity, magnetism, spin-crossover, chromism, is a great challenge and will lead this system to the next-generation of material science. 


\section{Acknowledgement}

We thank an Exploratory Research for Advanced Technology (ERATO) project by Japan Science and Technology Agency (JST) 'Kitagawa Integrated Pores Project'

\section{References}

1 E. Matisova and S. Skrabakova, J. Chromatogr. A, 1995, 707, 145-179.

2 T. Wigmans, Carbon, 1989, 27, 13-22.

3 M. E. Davis and R. F. Lobo, Chem. Mater., 1992, 4, 756-768.

4 G. A. Ozin, A. Kuperman and A. Stein, Angew. Chem. Int. Ed. Engl., 1989, 28, 359-376.

5 A. K. Cheetham, G. Ferey and T. Loiseau, Angew. Chem. Int. Ed., 1999, 38, 3268-3292.

6 S. Kitagawa and M. Kondo, Bull. Chem. Soc. Jpn., 1998, 71, 1739-1753.

7 O. M. Yaghi, H. L. Li, C. Davis, D. Richardson and T. L. Groy, Acc. Chem. Res., 1998, 31, 474-484.

8 S. R. Batten and R. Robson, Angew. Chem. Int. Ed., 1998, 37, 1460-1494.

9 A. J. Blake, N. R. Champness, P. Hubberstey, W. S. Li, M. A. Withersby and M. Schröder, Coord. Chem. Rev., 1999, 183, 117-138.

10 B. Moulton and M. J. Zaworotko, Chem. Rev., 2001, 101, 1629-1658.

11 M. Eddaoudi, D. B. Moler, H. L. Li, B. L. Chen, T. M. Reineke, M. O'Keeffe and O. M. Yaghi, Acc. Chem. Res., 2001, 34, 319-330.

12 S. L. James, Chem. Soc. Rev., 2003, 32, 276-288.

13 A. P. Côté and G. K. H. Shimizu, Coord. Chem. Rev., 2003, 245, 49-64.

14 G. S. Papaefstathiou and L. R. MacGillivray, Coord. Chem. Rev., 2003, 246, 169-184.

15 C. Janiak, Dalton Trans., 2003, 2781-2804.

16 S. Kitagawa, R. Kitaura and S. Noro, Angew. Chem. Int. Ed., 2004, 43, 2334-2375.

17 C. N. R. Rao, S. Natarajan and R. Vaidhyanathan, Angew. Chem. Int. Ed., 2004, 43, 1466-1496.

18 A. J. Fletcher, K. M. Thomas and M. J. Rosseinsky, J. Solid State Chem., 2005, 178, 2491-2510.

19 K. Uemura, R. Matsuda and S. Kitagawa, J. Solid State Chem., 2005, 178, 2420-2429.

20 U. Müller, M. Schubert, F. Teich, H. Puetter, K. Schierle-Arndt and J. Pastré, J. Mater. Chem., 2006, 16, 626-636.

21 D. Maspoch, D. Ruiz-Molina and J. Veciana, Chem. Soc. Rev., 2007, 36, 770-818.

22 R. E. Morris and P. S. Wheatley, Angew. Chem. Int. Ed., 2008, 47, 4966-4981.

23 J. Lee, O. K. Farha, J. Roberts, K. A. Scheidt, S. T. Nguyen and J. T. Hupp, Chem. Soc. Rev., 2009, 38, 1450-1459.

24 G. Ferey and C. Serre, Chem. Soc. Rev., 2009, 38, 1380-1399.

25 L. J. Murray, M. Dinca and J. R. Long, Chem. Soc. Rev., 2009, 38, 1294-1314.

26 R. A. Fischer and C. Woll, Angew. Chem. Int. Ed., 2009, 48, 6205-6208.

27 J. R. Li, R. J. Kuppler and H. C. Zhou, Chem. Soc. Rev., 2009, 38, 1477-1504.

28 L. Q. Ma, C. Abney and W. B. Lin, Chem. Soc. Rev., 2009, 38, 1248-1256.

29 B. L. Chen, S. C. Xiang and G. D. Qian, Acc. Chem. Res., 2010, 43, 1115-1124.

30 S. Horike, S. Shimomura and S. Kitagawa, Nat. Chem., 2009, 1, 695-704.

31 D. S. Acker and W. R. Hertler, J. Am. Chem. Soc., 1962, 84, 3370-3374.

32 W. R. Hertler, D. S. Acker, R. E. Benson and H. D. Hartzler, J. Am. Chem. Soc., 1962, 84, 3387-3393.

33 W. R. Hertler and R. E. Benson, J. Am. Chem. Soc., 1962, 84, 3474-3478.

34 L. R. Melby, W. Mahler, W. E. Mochel, R. J. Harder, W. R. Hertler and R. E. Benson, J. Am. Chem. Soc., 1962, 84, 3374-3387.

35 W. Kaim and M. Moscherosch, Coord. Chem. Rev., 1994, 129, 157-193.

36 L. Ballester, A. Gutierrez, M. F. Perpinan and M. T. Azcondo, Coord. Chem. Rev., 1999, 192, 
447-470

37 D. Jerome, Chem. Rev., 2004, 104, 5565-5591.

38 D. S. Acker, R. J. Harder, W. R. Hertler, W. Mahler, L. R. Melby, R. E. Benson and W. E. Mochel, J. Am. Chem. Soc., 1960, 82, 6408-6409.

39 J. Ferraris, V. Walatka, Perlstei.Jh and D. O. Cowan, J. Am. Chem. Soc., 1973, 95, 948-949.

40 L. B. Coleman, M. J. Cohen, D. J. Sandman, Yamagish.Fg, A. F. Garito and A. J. Heeger, Solid State Commun., 1973, 12, 1125-1132.

41 L. Shields, J. Chem. Soc., Faraday Trans. 2, 1985, 81, 1-9.

42 R. S. Potember, T. O. Poehler and D. O. Cowan, Appl. Phys. Lett., 1979, 34, 405-407.

43 R. S. Potember, T. O. Poehler and R. C. Benson, Appl. Phys. Lett., 1982, 41, 548-550.

44 Z. Z. Gu, H. M. Wu, Y. Wei and J. Z. Liu, J. Phys. Chem., 1993, 97, 2543-2545.

45 R. A. Heintz, H. H. Zhao, O. Y. Xiang, G. Grandinetti, J. Cowen and K. R. Dunbar, Inorg. Chem., 1999, 38, 144-156.

46 H. B. Liu, Q. Zhao, Y. L. Li, Y. Liu, F. S. Lu, J. P. Zhuang, S. Wang, L. Jiang, D. B. Zhu, D. P. Yu and L. F. Chi, J. Am. Chem. Soc., 2005, 127, 1120-1121.

47 A. P. O'Mullane, N. Fay, A. Nafady and A. M. Bond, J. Am. Chem. Soc., 2007, 129, 2066-2073.

48 D. J. Flannigan, V. A. Lobastov and A. H. Zewail, Angew. Chem. Int. Ed., 2007, 46, 9206-9210.

49 H. Miyasaka, C. S. Campos-Fernandez, R. Clerac and K. R. Dunbar, Angew. Chem. Int. Ed., 2000, 39, 3831-3832.

50 H. Miyasaka, T. Izawa, N. Takahashi, M. Yamashita and K. R. Dunbar, J. Am. Chem. Soc., 2006, 128, 11358-11359.

51 H. Miyasaka, N. Motokawa, S. Matsunaga, M. Yamashita, K. Sugimoto, T. Mori, N. Toyota and K. R. Dunbar, J. Am. Chem. Soc., 2010, 132, 1532-1544.

52 V. Dong, H. Endres, H. J. Keller, W. Moroni and D. Nothe, Acta Crystallogr., Sect. B: Struct. Sci., 1977, 33, 2428-2431.

53 H. H. Zhao, R. A. Heintz, K. R. Dunbar and R. D. Rogers, J. Am. Chem. Soc., 1996, 118, 12844-12845.

54 H. Zhao, R. A. Heintz, X. Ouyang, K. R. Dunbar, C. F. Campana and R. D. Rogers, Chem. Mater., 1999, 11, 736-746.

55 Y. Shibata, J. Coll. Sci., Imp. Univ. Tokyo, 1916, 37, 1-31.

56 J. F. Keggin and F. D. Miles, Nature, 1936, 137, 577-578.

57 M. Kondo, T. Yoshitomi, K. Seki, H. Matsuzaka and S. Kitagawa, Angew. Chem. Int. Ed. Engl., 1997, 36, 1725-1727.

58 H. Li, M. Eddaoudi, M. O'Keeffe and O. M. Yaghi, Nature, 1999, 402, 276-279.

59 M. Eddaoudi, J. Kim, N. Rosi, D. Vodak, J. Wachter, M. O'Keeffe and O. M. Yaghi, Science, 2002, 295, 469-472.

60 H. K. Chae, D. Y. Siberio-Perez, J. Kim, Y. Go, M. Eddaoudi, A. J. Matzger, M. O'Keeffe and O. M. Yaghi, Nature, 2004, 427, 523-527.

61 H. Furukawa, N. Ko, Y. B. Go, N. Aratani, S. B. Choi, E. Choi, A. O. Yazaydin, R. Q. Snurr, M. O'Keeffe, J. Kim and O. M. Yaghi, Science, 2010, 329, 424-428.

62 S. S. Y. Chui, S. M. F. Lo, J. P. H. Charmant, A. G. Orpen and I. D. Williams, Science, 1999, 283, 1148-1150.

63 D. F. Sun, S. Q. Ma, Y. X. Ke, D. J. Collins and H. C. Zhou, J. Am. Chem. Soc., 2006, 128, 3896-3897.

64 G. Ferey, C. Mellot-Draznieks, C. Serre, F. Millange, J. Dutour, S. Surble and I. Margiolaki, Science, 2005, 309, 2040-2042.

65 K. S. Park, Z. Ni, A. P. Cote, J. Y. Choi, R. D. Huang, F. J. Uribe-Romo, H. K. Chae, M. O'Keeffe and O. M. Yaghi, Proc. Natl. Acad. Sci. USA, 2006, 103, 10186-10191.

66 K. S. W. Sing, D. H. Everett, R. A. W. Haul, L. Moscou, R. A. Pierotti, J. Rouquerol and T. Siemieniewska, Pure Appl. Chem., 1985, 57, 603-619.

67 D. Li and K. Kaneko, Chem. Phys. Lett., 2001, 335, 50-56.

68 A. Kondo, H. Noguchi, S. Ohnishi, H. Kajiro, A. Tohdoh, Y. Hattori, W. C. Xu, H. Tanaka, H. 
Kanoh and K. Kaneko, Nano Lett., 2006, 6, 2581-2584.

R. Kitaura, K. Seki, G. Akiyama and S. Kitagawa, Angew. Chem. Int. Ed., 2003, 42, 428-431. Y. Inubushi, S. Horike, T. Fukushima, G. Akiyama, R. Matsuda and S. Kitagawa, Chem. Commun., 2010, DOI: 10.1039/C1030CC01294G.

S. Horike, D. Tanaka, K. Nakagawa and S. Kitagawa, Chem. Commun., 2007, 3395-3397.

R. Kitaura, K. Fujimoto, S. Noro, M. Kondo and S. Kitagawa, Angew. Chem. Int. Ed., 2002, 41, 133-135.

H. J. Choi, M. Dinca and J. R. Long, J. Am. Chem. Soc., 2008, 130, 7848-7850.

C. J. Kepert and M. J. Rosseinsky, Chem. Commun., 1999, 375-376.

K. Barthelet, J. Marrot, D. Riou and G. Ferey, Angew. Chem. Int. Ed., 2002, 41, 281-284.

L. Alaerts, C. E. A. Kirschhock, M. Maes, M. A. van der Veen, V. Finsy, A. Depla, J. A. Martens, G. V. Baron, P. A. Jacobs, J. E. M. Denayer and D. E. De Vos, Angew. Chem. Int. Ed., 2007, 46, 4293-4297.

D. N. Dybtsev, H. Chun and K. Kim, Angew. Chem. Int. Ed., 2004, 43, 5033-5036.

H. Chun, D. N. Dybtsev, H. Kim and K. Kim, Chem. Eur. J., 2005, 11, 3521-3529.

B. Q. Ma, K. L. Mulfort and J. T. Hupp, Inorg. Chem., 2005, 44, 4912-4914.

O. K. Farha and J. T. Hupp, Acc. Chem. Res., 2010, 43, 1166-1175.

B. L. Chen, C. D. Liang, J. Yang, D. S. Contreras, Y. L. Clancy, E. B. Lobkovsky, O. M. Yaghi and S. Dai, Angew. Chem. Int. Ed., 2006, 45, 1390-1393.

J. P. Zhang and X. M. Chen, J. Am. Chem. Soc., 2008, 130, 6010-6017.

S. Galli, N. Masciocchi, V. Colombo, A. Maspero, G. Palmisano, F. J. Lopez-Garzon, M. Domingo-Garcia, I. Fernandez-Morales, E. Barea and J. A. R. Navarro, Chem. Mater, 2010, 22, 1664-1672.

K. Schlichte, T. Kratzke and S. Kaskel, Microporous Mesoporous Mater., 2004, 73, 81-88.

B. L. Chen, N. W. Ockwig, A. R. Millward, D. S. Contreras and O. M. Yaghi, Angew. Chem. Int. Ed., 2005, 44, 4745-4749.

X. Lin, J. H. Jia, X. B. Zhao, K. M. Thomas, A. J. Blake, G. S. Walker, N. R. Champness, P. Hubberstey and M. Schroder, Angew. Chem. Int. Ed., 2006, 45, 7358-7364.

P. D. C. Dietzel, B. Panella, M. Hirscher, R. Blom and H. Fjellvag, Chem. Commun., 2006, 959-961.

P. D. C. Dietzel, R. E. Johnsen, H. Fjellvag, S. Bordiga, E. Groppo, S. Chavan and R. Blom, Chem. Commun., 2008, 5125-5127.

S. Kitagawa, S. Noro and T. Nakamura, Chem. Commun., 2006, 701-707.

B. F. Abrahams, B. F. Hoskins, D. M. Michail and R. Robson, Nature, 1994, 369, 727-729.

M. E. Kosal, J. H. Chou, S. R. Wilson and K. S. Suslick, Nat. Mater., 2002, 1, 118-121.

R. Kitaura, G. Onoyama, H. Sakamoto, R. Matsuda, S. Noro and S. Kitagawa, Angew. Chem. Int. Ed., 2004, 43, 2684-2687.

S. H. Cho, B. Q. Ma, S. T. Nguyen, J. T. Hupp and T. E. Albrecht-Schmitt, Chem. Commun., 2006, 2563-2565.

R. Q. Zou, H. Sakurai, S. Han, R. Q. Zhong and Q. Xu, J. Am. Chem. Soc., 2007, 129, 8402-8403.

M. Tonigold, Y. Lu, B. Bredenkotter, B. Rieger, S. Bahnmuller, J. Hitzbleck, G. Langstein and D. Volkmer, Angew. Chem. Int. Ed., 2009, 48, 7546-7550.

L. J. Murray, M. Dinca, J. Yano, S. Chavan, S. Bordiga, C. M. Brown and J. R. Long, J. Am. Chem. Soc., 2010, 132, 7856-7857.

K. L. Mulfort and J. T. Hupp, J. Am. Chem. Soc., 2007, 129, 9604-9605.

D. Himsl, D. Wallacher and M. Hartmann, Angew. Chem. Int. Ed., 2009, 48, 4639-4642.

C. D. Wu and W. B. Lin, Angew. Chem. Int. Ed., 2007, 46, 1075-1078.

Z. Q. Wang and S. M. Cohen, Chem. Soc. Rev., 2009, 38, 1315-1329.

S. Couck, J. F. M. Denayer,
Soc., 2009, 131, 6326-6327.

2 C. Volkringer and S. M. Cohen, Angew. Chem. Int. Ed., 2010, 49, 4644-4648.

3 H. Sato, R. Matsuda, K. Sugimoto, M. Takata and S. Kitagawa, Nat. Mater., 2010, 9, 661-666.

4 O. Ohmori, M. Kawano and M. Fujita, J. Am. Chem. Soc., 2004, 126, 16292-16293. 
105 Y. E. Cheon and M. P. Suh, Angew. Chem. Int. Ed., 2009, 48, 2899-2903.

106 Q. X. Yao, L. Pan, X. H. Jin, J. Li, Z. F. Ju and J. Zhang, Chem. Eur. J., 2009, 15, 11890-11897.

107 S. Shimomura, R. Matsuda, T. Tsujino, T. Kawamura and S. Kitagawa, J. Am. Chem. Soc., 2006, 128, 16416-16417.

108 B. F. Abrahams, R. W. Elliott, T. A. Hudson and R. Robson, Cryst. Growth Des., 2010, 10, 2860-2862.

109 S. Shimomura, S. Horike, R. Matsuda and S. Kitagawa, J. Am. Chem. Soc., 2007, 129, 10990-10991.

110 S. Shimomura, R. Matsuda and S. Kitagawa, Chem. Mater., 2010, 22, 4129-4131.

111 S. Shimomura, M. Higuchi, R. Matsuda, K. Yoneda, Y. Hijikata, Y. Kubota, Y. Mita, J. Kim, M. Takata and S. Kitagawa, Nat. Chem., 2010, 2, 633-637.

112 N. Motokawa, S. Matsunaga, S. Takaishi, H. Miyasaka, M. Yamashita and K. R. Dunbar, J. Am. Chem. Soc., 2010, 132, 11943-11951. 


\section{Figure Captions}

Figure 1. Crystal structures of (a) AgTCNQ and (b) CuTCNQ (phase II). Blue sphere, light blue sphere, cadet blue and gray represent $\mathrm{Cu}, \mathrm{Ag}, \mathrm{N}$, and $\mathrm{C}$ atoms, respectively. $\mathrm{H}$ atoms are omitted for clarity. CuTCNQ (phase I) possesses isomorphic structure of AgTCNQ.

Figure 2. A crystal structure of $\left[\mathrm{Ru}_{2}\left(\mathrm{O}_{2} \mathrm{CCF}_{3}\right)\left(\mu_{4}-\mathrm{TCNQ}\right)\right]$. Deep green sphere, light green, red, cadet blue, and gray represent $\mathrm{Ru}, \mathrm{F}, \mathrm{O}, \mathrm{N}$, and $\mathrm{C}$ atoms, respectively. $\mathrm{H}$ atoms are omitted for clarity.

Figure 3. Crystal structures of several 3D robust MOFs with high porosity.

Figure 4. Classification of PCPs. The first-generation materials collapse on guest removal. The second-generation materials have robust and rigid frameworks, and retain their crystallinity when the guests are not present in the pores. The third-generation materials are transformable accompanied by structural transformation.

Figure 5. Crystal structures of 2D PCPs (a) $\left[\mathrm{Cu}\left(\mathrm{BF}_{4}\right)_{2}(\mathrm{bpy})_{2}\right]$ and (b) $[\mathrm{Zn}(\mathrm{ip})(\mathrm{bpy})]$, and their schematic views showing structural transformations accompanying with guest accommodation. Blue sphere, yellow sphere, pink, light green, red, cadet blue, and gray represent $\mathrm{Cu}, \mathrm{Zn}, \mathrm{P}, \mathrm{F}, \mathrm{O}, \mathrm{N}$, and $\mathrm{C}$ atoms, respectively. $\mathrm{H}$ atoms are omitted for clarity.

Figure 6. Crystal structures of flexible 3D PCPs (a) [V(OH)(BDC)] (MIL-47), (b) $\left[\mathrm{Zn}_{2}(\mathrm{bdc})_{2}(\mathrm{dabco})\right]$ and (c) $\left[\mathrm{Zn}_{2}(\mathrm{bdc})_{2}(\mathrm{bpy})\right](\mathrm{MOF}-508)$. Dark gray sphere, yellow sphere, red cadet blue, and gray represent $\mathrm{V}, \mathrm{Zn}, \mathrm{O}, \mathrm{N}$, and $\mathrm{C}$ atoms, respectively. $\mathrm{H}$ atoms are omitted for clarity.

Figure 7. (a) $\mathrm{A} \mathrm{CO}_{2}$ binding structure of $\left[\mathrm{Ni}_{2}(\mathrm{DHBDC})\right]$ (CPO-27-Ni or Ni-MOF-74). Oxygen atom of $\mathrm{CO}_{2}$ coordinated to the open $\mathrm{Ni}$ site. Dark blue sphere, red and gray represent $\mathrm{Ni}, \mathrm{O}$, and $\mathrm{C}$ atoms, respectively. $\mathrm{H}$ atoms are omitted for clarity. (b) A crystal structure of $\left[\mathrm{Cd}_{3} \mathrm{~L}_{4}\left(\mathrm{NO}_{3}\right)_{6}\right]$ and schematic representation of an asymmetric addition reaction of diethylzinc to aromatic aldehydes. Yellow sphere, green, red, cadet blue, and gray represent $\mathrm{Zn}, \mathrm{Cl}, \mathrm{O}, \mathrm{N}$, and $\mathrm{C}$ atoms, respectively. $\mathrm{H}$ atoms are omitted for clarity.

Figure 8. Crystal structures of TCNQ based PCPs (a) [Zn(TCNQ)bpy] and (b) [Zn(TCNQ-TCNQ)bpy]. Yellow sphere, cadet blue, and gray represent $\mathrm{Zn}, \mathrm{N}$, and $\mathrm{C}$ atoms, respectively. $\mathrm{H}$ atoms are omitted for clarity. 
Figures

(a)

(b)
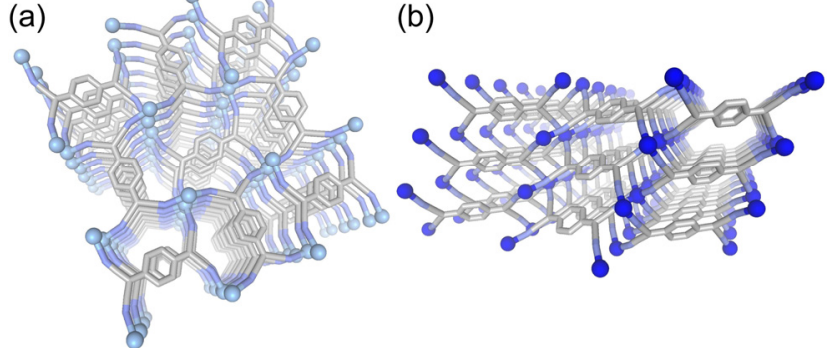

Figure 1

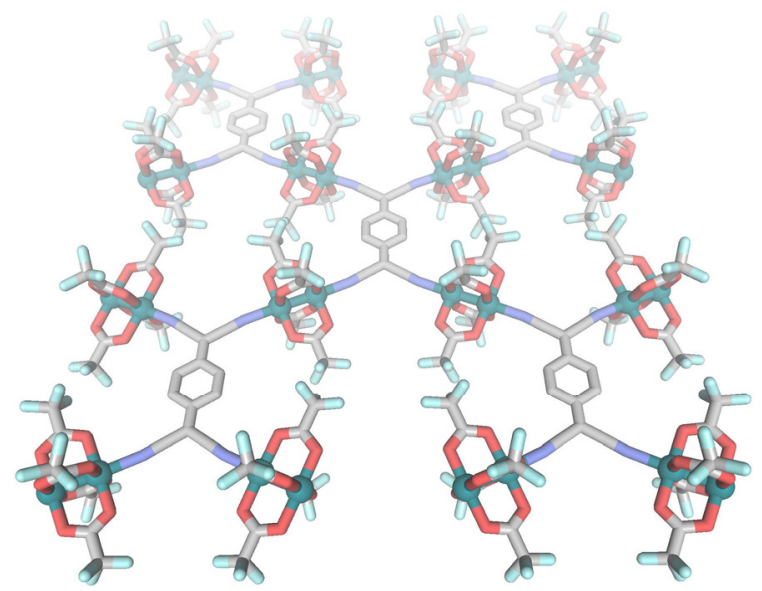

Figure 2 

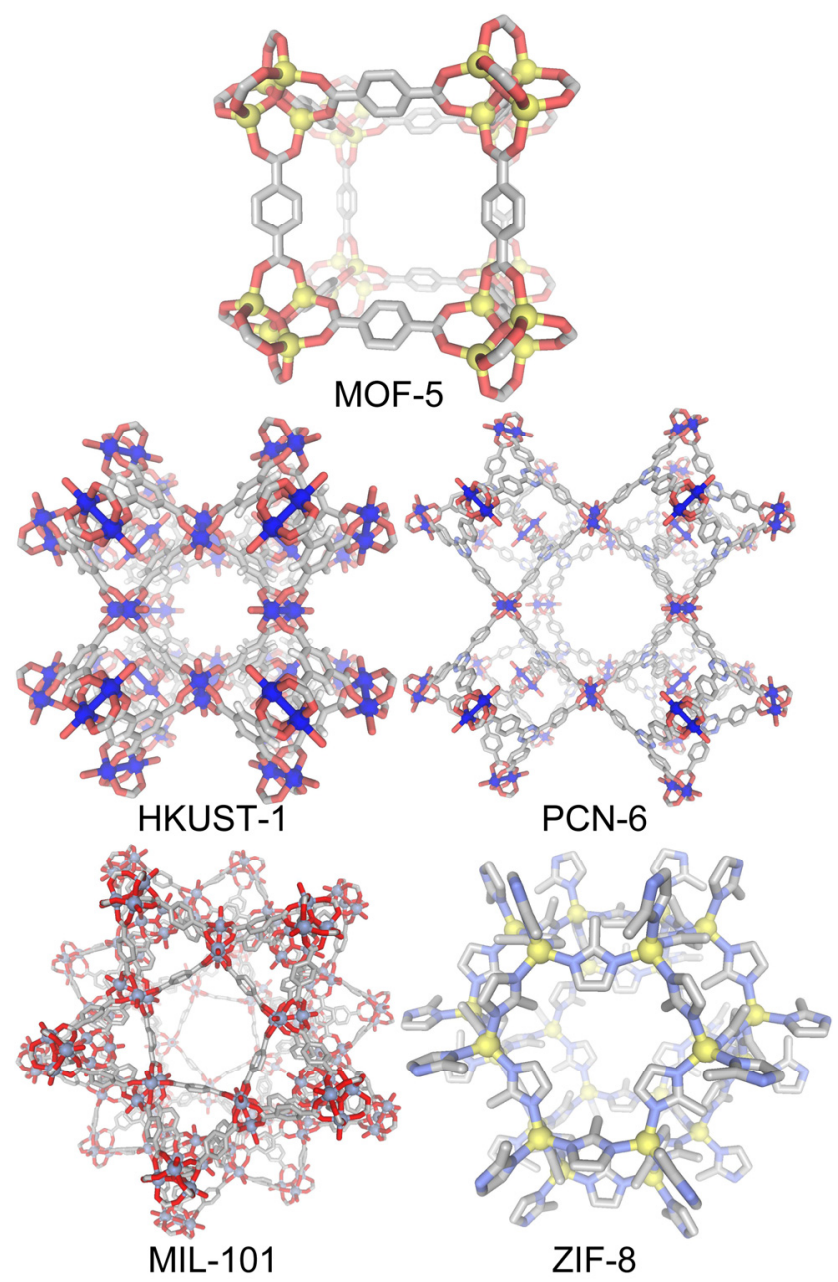

Figure 3 
1st Generation
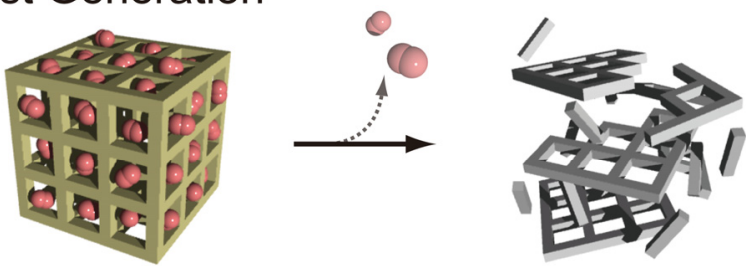

2nd Generation
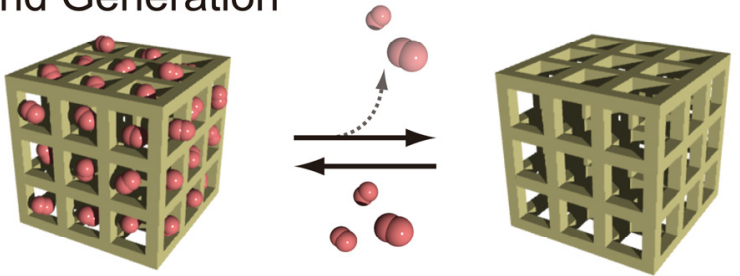

3rd Generation
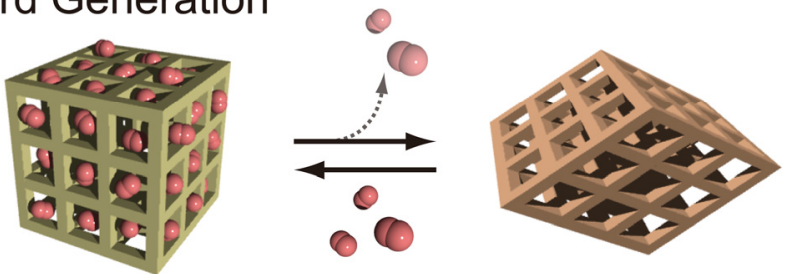

Figure 4

(a)
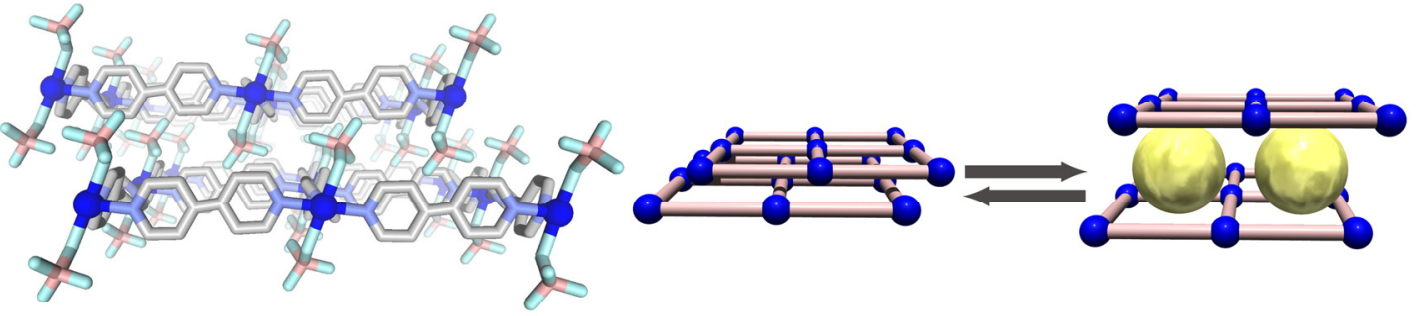

(b)
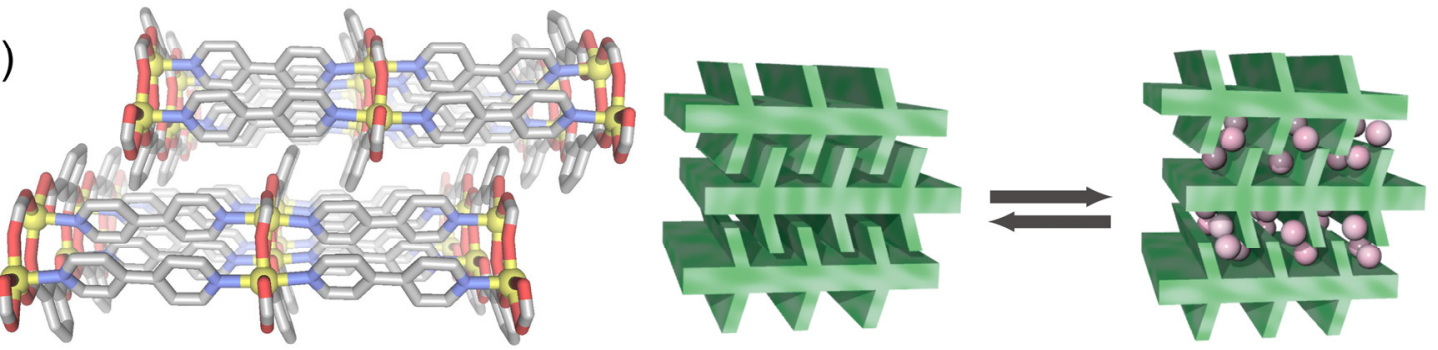

Figure 5 

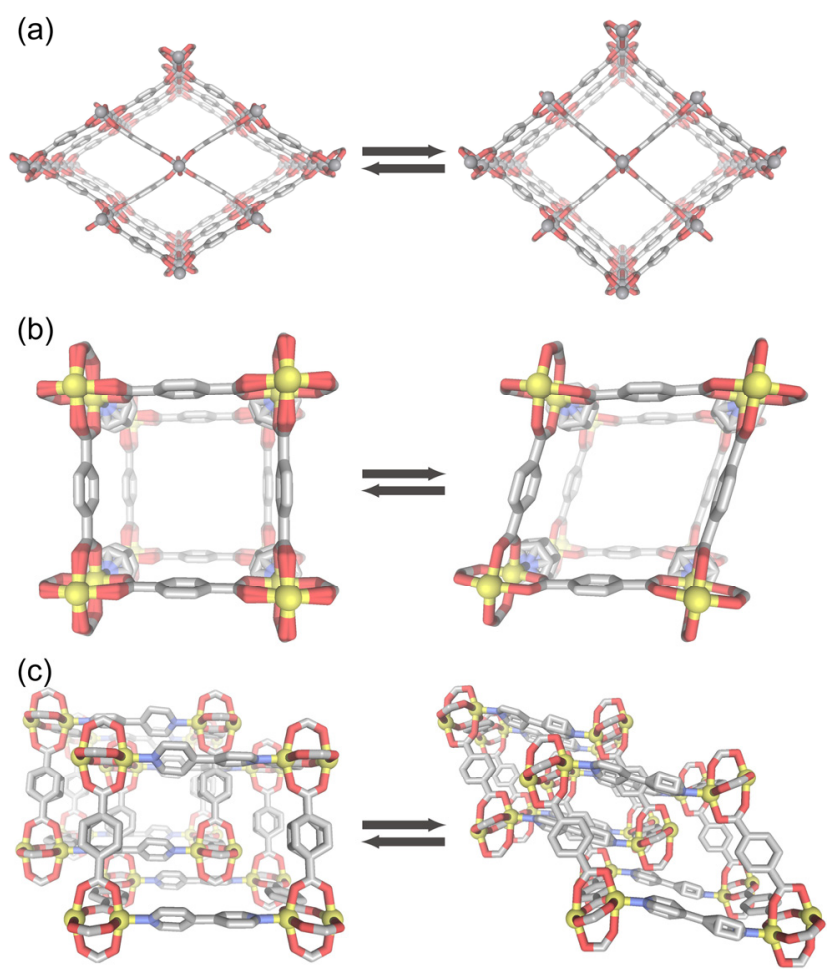

Figure 6

(a)

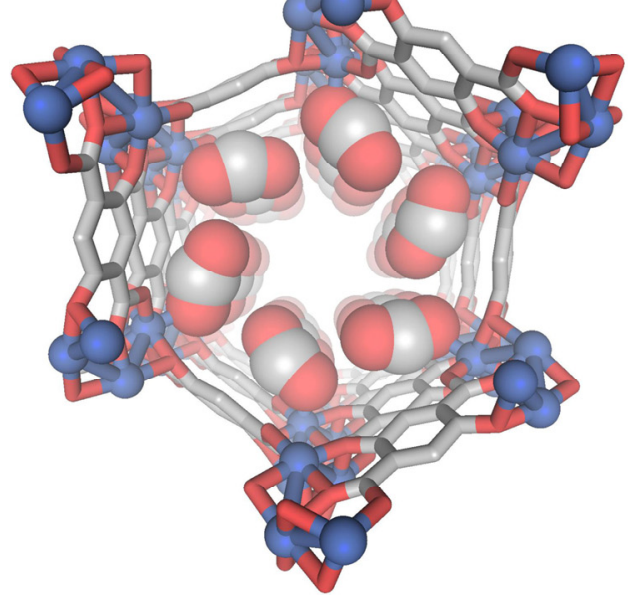

(b)

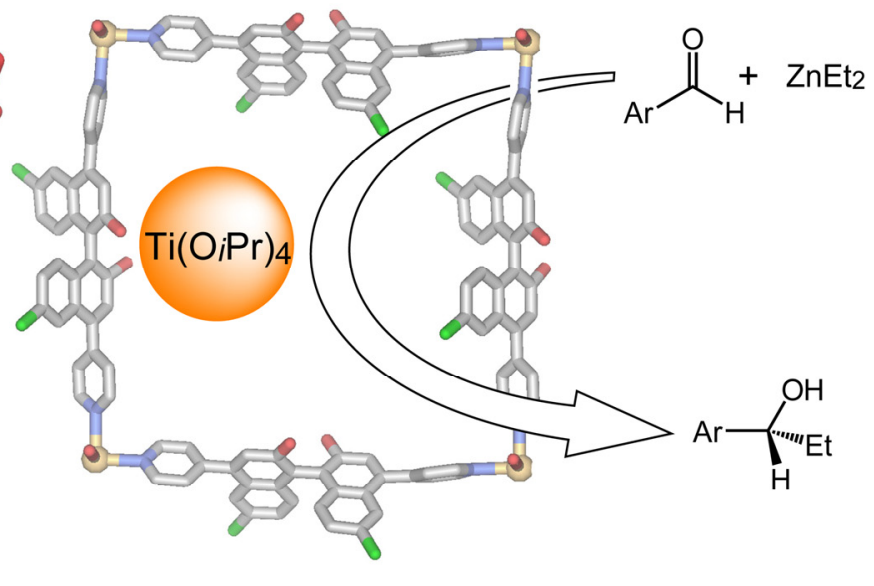

Figure 7 

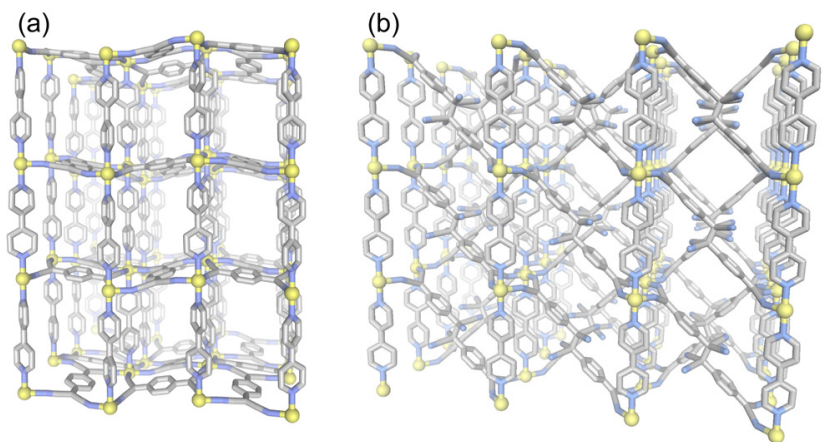

Figure 8 